\title{
Thermodynamic Modeling of Sustainable Non-ferrous Metals Production: Part I
}

\author{
FISEHA TESFAYE ®i], ${ }^{1,4}$ ALEXANDRA E. ANDERSON, ${ }^{2,5}$ \\ and MINGMING ZHANG ${ }^{3,6}$ \\ 1.-Johan Gadolin Process Chemistry Centre, Ảbo Akademi University, Piispankatu 8, \\ 20500 Turku, Finland. 2.-Gopher Resource, 6505 Jewel Ave, Tampa, FL, USA. \\ 3.-ArcelorMittal Global R\&D, East Chicago, USA. 4.-e-mail: fiseha.tesfaye@abo.fi. \\ 5.—e-mail: allieanderson0@gmail.com. 6.-e-mail: Mingming.Zhang@arcelormittal.com
}

The conventional non-ferrous metal production processes were developed when scarcity of natural resources and environmental impacts were not issues. Currently, there are efforts underway to advance sustainable metallurgical processes that enable resource efficiency. The recent increase in non-ferrous metal demand, complexities of the available raw materials, and Earth's intrinsic limitations pose a challenge to the prevailing sustainable production of the metals.

The global increase in the demand for non-ferrous metals has also amplified their recovery from waste streams. While efficiency in the recovery of resources from waste streams is important in closing the metals loop, emphasis should also be placed on advancing the current primary resource processing technologies to reduce environmental footprints and improve energy efficiency. The widely applied extraction methods via hydrometallurgy processing routes are carried out using a large volume of acids. Future research should also focus on creating an alternative strategy such as applying novel electrochemical extraction methods that could be more sustainable.

Recently, JOM advisors of the Recycling and Environmental Technologies Committee have organized special topics on "Recycling of Industrial Metals and Materials: Trends in Recent Research" and "Cleaner Manufacturing of Critical Metals". The articles published on these topics were focused on various improvements in process flowsheets that send intermediate products and residues back as feedstock to a process as well as the circular economy of critical metals. In the present topic,

The Thermodynamic Modeling of Sustainable Non-Ferrous Metals Production topic was organized by Fiseha Tesfaye, JOM Advisor, Process Technology and Modeling Committee; Alexandra Anderson, Guest Editor, Process Technology and Modeling Committee; and Mingming Zhang, JOM Advisor, Recycling and Environmental Technologies Committee. papers covering experimental investigations, thermodynamic modeling, metallurgical process optimization, resource efficiency, and environmental issues, particularly those pertaining to non-ferrous metallurgical processes, were invited, and four articles were approved for publication in Part I of the two-part topic.

The papers are primarily devoted to promoting improved and sustainable ways of producing platinum group metals (PGMs) and rare earth metals (REMs) from both primary and secondary sources. The first three papers focus on different REM recovery techniques and exergetic analysis. The paper "Recovery of Scandium from Reservoir Silt by Electric Separation" by Guifang Zhang et al. contributes to the development of a pilot-scale beneficiation process for scandium recovery through the electrical separation technique. The second paper, "Dissolution Behavior of a Rare-Earth Metal in $\mathrm{H}_{2} \mathrm{SO}_{4}-\mathrm{H}_{3} \mathrm{PO}_{4}-\mathrm{H}_{3} \mathrm{PW}_{12} \mathrm{O}_{40}$ Solution" by Xingyu Chen et al., investigated the dissolution behavior of lanthanum sulfate in $\mathrm{H}_{2} \mathrm{SO}_{4}-\mathrm{H}_{3} \mathrm{PO}_{4}-\mathrm{H}_{3} \mathrm{PW}_{12} \mathrm{O}_{40}$ in different acid concentrations and temperature conditions. The third paper, "A Simulation-Based Exergetic Analysis of NdFeB Permanent Magnet Production to Understand Large Systems" by Ivan Belo Fernandes et al., evaluates the production of $\mathrm{NdFeB}$ permanent magnets through a simulationbased lifecycle assessment and exergetic analysis, comprising 107 unit operations, 361 flows, and 209 compounds. The research highlights the environmental impact and resource efficiency for production of $\mathrm{NdFeB}$ permanent magnets from a monaziterich deposit in Brazil by performing an exergetic evaluation in addition to the usual energy analysis of the production process at the unit operation level, i.e., from ore to magnet. 
The fourth paper, "Control of Platinum Loss in WEEE Smelting" by Lassi Klemettinen et al., focused on investigation of the dissolution of platinum in alumina spinel-saturated iron silicate slags at high temperature and in copper smelting and refinery conditions. Results observed in their study suggest the pyrometallurgical processing route is highly efficient for PGM recycling.

The organizers of this special topic believe that the papers make an impact on both academia and industrial $R \& D$ efforts to reduce environmental footprints while promoting sustainable production of PGMs and REMs meeting future demands. All titles and authors of the articles published under the topic "Thermodynamic Modeling of Sustainable Non-Ferrous Metals Production: Part I" in the July 2020 issue (vol. 72, no. 7) of JOM are listed below. Part II of this topic will be published in the September 2020 issue. The articles included in Part I can be fully accessed via the journal's page at http://link.springer.com/journal/11837/72/7/page/1.

- "Recovery of Scandium from Reservoir Silt by Electric Separation” by G. Zhang, P. Yan, Y. Yang, and A. McLean.

- "Dissolution Behavior of a Rare-Earth Metal in $\mathrm{H}_{2} \mathrm{SO}_{4}-\mathrm{H}_{3} \mathrm{PO}_{4}-\mathrm{H}_{3} \mathrm{PW}_{12} \mathrm{O}_{40}$ Solution" by X. Chen, F. Guo, Q. Chen, X. Liu, X. Ma, and Z. Zhao.

- "A Simulation-Based Exergetic Analysis of $\mathrm{NdFeB}$ Permanent Magnet Production to Under- stand Large Systems" by I.B. Fernandes, A.A. Llamas, and M.A. Reuter.

- "Control of Platinum Loss in WEEE Smelting" by L. Klemettinen, K. Avarmaa, H. O'Brien, A. Jokilaakso, and P. Taskinen.

\section{ACKNOWLEDGEMENTS}

We thank all authors, co-authors, and reviewers that have contributed to this special issue. We are convinced that your expertise has resulted in an excellent issue on this timely topic of JOM. We are also most grateful to Editor Maureen Byko for always providing answers to our endless stream of technical questions. The authors are also grateful to the Academy of Finland (Decision No. 311537) for financial support as part of the activities of the Johan Gadolin Process Chemistry Centre at Ảbo Akademi University.

\section{REFERENCES}

1. D.E. Verhulst, F. Tesfaye, and M.E. Schlesinger, JOM 71, 3164 (2019). https://doi.org/10.1007/s11837-019-03663-w.

2. F. Tesfaye, N. Ma, and M. Zhang, JOM 72, 764 (2020). https://doi.org/10.1007/s11837-019-03976-w.

Publisher's Note Springer Nature remains neutral with regard to jurisdictional claims in published maps and institutional affiliations. 